\title{
Quantitative electromyography using automatic analysis: studies in healthy subjects and patients with primary muscle disease
}

\author{
A. L. ROSE AND R. G. WILLISON
}

From the Institute of Neurology, Queen Square, London

The difficulties of subjective assessment of the electromyogram are well known. It is possible to recognize gross disorders by the appearance of the trace on the cathode-ray tube and by the sound in the loud speaker, but the evaluation of mild changes is more difficult. In order to overcome this, a method of quantitative analysis has been developed which has been described in previous papers (Willison, 1963 ; 1964). The original technique involved counting every potential change greater than $100 \mu \mathrm{V}$ in recordings taken with a concentric needle electrode during voluntary effort against a standard load. When the triceps muscle was studied, it was found that a voluntary contraction against a $2 \mathrm{~kg}$. load produced a much greater number of potential changes per second in dystrophic patients than in healthy subjects, the count rate (i.e., the number of potential changes per second) showing some relation to the severity of the muscle disease. At that time photographic records were analysed with a

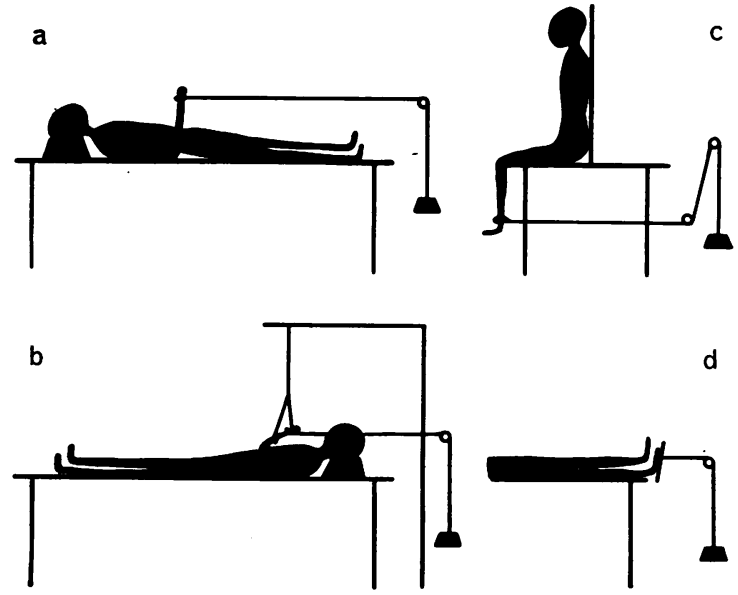

FIG. 1. Posture of subject and position of slings during examination of (a) biceps; (b) triceps; (c) vastus medialis; (d) tibialis anterior. special mechanical counting device. The measurement of even short lengths of record was laborious and it soon became obvious that rapid automatic measurement would have to be used in order to obtain enough figures to put the technique on a statistical basis. In the present work we have used electronic analysers to count potential changes and measure potential amplitudes as the record is being taken. This makes it possible to obtain results from several areas in one muscle in a relatively short time and to examine several muscles when necessary.

The present paper reports observations on the biceps brachii, triceps, vastus medialis, and tibialis anterior. The analysers which have been used follow the general design described by Fitch and Willison (1965); details of the electronic circuits will be published elsewhere (Fitch, 1967) and only a summary of the principles of operation will be given here.

\section{MATERIAL AND METHODS}

Observations were made on 45 control subjects and 20 patients with muscular dystrophy or polymyositis, The ages of the healthy subjects ranged from 20 to 47 years and of the patients from 11 to 65 years. In order to obtain isometric contractions at standard loads the positions shown in Fig. 1 a-d were used. For biceps the subject lay supine (Fig. 1a) with the elbow at a right angle. For triceps (Fig. 1b) the limb was supported by slings from a jib so that the forearm was clear of the chest wall. In both cases the elbow was maintained at a right angle and the forearm maintained midway between pronation and supination. For the examination of the vastus medialis (Fig. 1c) the subject sat on the end of the couch with the knee bent and the foot hanging. For the tibialis anterior (Fig. 1d) the subject lay supine and a piece of resin-bonded paper board was strapped to the sole of the foot with scotch tape. The tape was placed mainly across the line of the metatarsal heads so that dorsiflexion of the great toe did not contribute to load bearing. A peg fixed through the board lay in the first interdigital cleft. The load was applied to each muscle by means of a nylon cord which was attached to 
a webbing cuff round the wrist or ankle, or attached directly to the footboard in the case of the tibialis anterior. Yacht blocks were used as pulleys and the static friction was less than $0 \cdot 2 \mathrm{~kg}$. with a load of $5 \mathrm{~kg}$. The main stand was a cast steel rack which provided rigid support both for the weights and for the jib which extended above the patient and to which webbing slings were attached for supporting the limb. In the examination of the tibialis anterior the footboard required support from the jib to prevent excessive plantar flexion which caused needle movement during relaxation.

In order to ensure that the length of the muscle was approximately constant during voluntary contraction two lamps were placed within sight of the subject. These lamps were illuminated by means of contacts placed at the top and bottom of a window cut in a sheet of nylon which carried the weight (Fig. 2). The central support consisted of a metal rod attached to the main rame. This acted as a mechanical stop for the weight and as the supply line for the two lamps. Thus, when the weight was carried by the upper contact the lower lamp was illuminated and indicated to the subject that he was not supporting the weight. As the muscle contracted the weight rose and further contraction brought the lower contact against the central support. The upper lamp was then illuminated and indicated to the subject that contraction was excessive. Both lamps remained off when the weight was hanging freely, supported only by the muscular effort. The vertical excursion of the weight was restricted to approximately $1 \mathrm{~cm}$. so that the angle of the joint remained almost constant. Nearly all subjects and patients easily learned to keep both lamps off; the lamps also indicated to the observer that the analysis of the electromyogram was carried out with the load correctly supported.

Before recording the electromyogram at a standard load, maximal voluntary power exerted by the muscle was measured by means of a spring balance and sling. The tensions achieved by patients with primary muscle disease during maximal effort were often substantially less than those of healthy subjects. In both groups, however, electromyographic activity was recorded during isometric contraction against the same standard loads of $2 \mathrm{~kg}$. for the biceps, triceps, and tibialis anterior and $5 \mathrm{~kg}$. for the vastus medialis. The reasons for selecting these standard loads, regardless of the patients' maximal capability, were discussed in a previous paper (Willison, 1964).

Four concentric needle electrodes (DISA Electronik, type $13 \mathrm{~K} \mathrm{51)}$ were used in the study. Their length was $30 \mathrm{~mm}$., outside diameter $0.45 \mathrm{~mm}$., core area $0.07 \mathrm{~mm}^{2}$. and bevel angle $15^{\circ}$. Before insertion each needle was prepared in $0.9 \%$ saline by applying $3 \mathrm{~V} \mathrm{AC}$ at $50 \mathrm{c} / \mathrm{s}$ across core and shaft with a suitable meter in series. The meter was calibrated and a minimum impedance of 2.5 to 7 kilohms was usually reached a few seconds after the voltage was applied. If it did not do so the needle was wiped firmly with a sterile swab and the voltage reapplied. The needle led through its standard cable and socket to a pair of cathode-follower input stages mounted on the couch. The screen of the cable was taken to one cathode and the subject was earthed

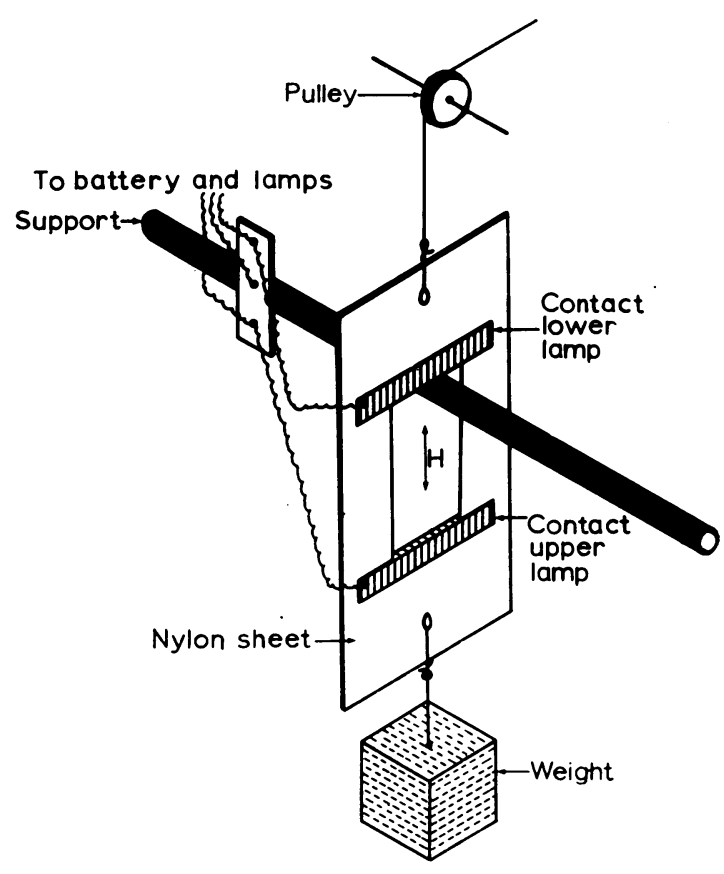

FIG. 2. Detail of weight support and window in nylon sheet with electrical contacts for lamp. The distance $₫$ of travel indicated by $H$ is adjustable; for clarity the lower contact is shown in its lowest position.

by means of a metal plate $3.5 \times 6 \mathrm{~cm}$. strapped to thece limb under examination. The core and shaft of the needle? were connected via $0 \cdot 15 \mathrm{mfd}$ capacitors to the grids of the Nuvistor triodes used in the cathode followers. The input impedance of each half to earth was approximately equivalent to 70 megohms with $30 \mathrm{pf}$ in parallel. The output impedance of the cathode-followers was 4 kilohms and long leads were taken to a Tektronix F.M. 122 preamplifier and Tektronix 502A oscilloscope. The frequency response of the preamplifier was $3 \mathrm{db}$. down at $40 \mathrm{kc} / \mathrm{s}$ and $8 \mathrm{c} / \mathrm{s}$ and the amplification was approximately 1,000 times.

The analysers were designed to reproduce as closely as possible the mechanical counting method used previously (Willison, 1963). One analyser measured all positive-going and negative-going potential changes greater than $100 \mu \mathrm{V}$ in amplitude, irrespective of their level with regard to the baseline (see Fig. 2 in Willison, 1966). The potential changes were counted and the total was displayed at the end of a timed period by a four-digit electronic counter. The number of potential changes per second will be referred to as the counts per second. The second analyser measured the amplitude of every potential change greater than $100 \mu \mathrm{V}$. This total was displayed (in units of $100 \mu \mathrm{V}$ ) on a six-digit electronic counter at the end of the same period of time.

The analysers were always calibrated before use by applying a suitably shaped signal of $1 \mathrm{mV}$ amplitude 
TABLE I

RESULTS IN FOUR MUSCLES IN HEALTHY SUBJECTS

\begin{tabular}{|c|c|c|c|c|c|c|c|}
\hline \multirow[t]{2}{*}{ Muscle } & \multirow{2}{*}{$\begin{array}{l}\text { No of Subjects } \\
\text { Examined }\end{array}$} & \multirow{2}{*}{$\begin{array}{l}\text { Standard Load } \\
(\mathrm{kg} .)\end{array}$} & \multirow{2}{*}{$\begin{array}{l}\text { Range of } \\
\text { Maximum } \\
\text { Tensions }{ }^{1} \text { (kg.) }\end{array}$} & \multicolumn{4}{|c|}{ Potential Changes per Second } \\
\hline & & & & $\begin{array}{l}\text { Range of Individual } \\
\text { Means }\end{array}$ & $\begin{array}{l}\text { Group } \\
\text { Mean }\end{array}$ & Standard Deviation & $\begin{array}{l}\text { Mean } \\
\quad+2 S . D .\end{array}$ \\
\hline $\begin{array}{l}\text { Biceps brachii } \\
\text { Triceps } \\
\text { Vastus medialis } \\
\text { Tibialis anterior }\end{array}$ & $\begin{array}{l}15 \\
11 \\
15 \\
20\end{array}$ & $\begin{array}{l}2 \\
2 \\
5 \\
2\end{array}$ & $\begin{array}{c}20-30 \\
7-19 \\
18-30+ \\
14-21\end{array}$ & $\begin{array}{l}140-308 \\
205-444 \\
145-356 \\
148-441\end{array}$ & $\begin{array}{l}246 \\
329 \\
246 \\
295\end{array}$ & $\begin{array}{l}56 \\
49 \\
52 \\
87\end{array}$ & $\begin{array}{l}358 \\
427 \\
350 \\
469\end{array}$ \\
\hline
\end{tabular}

Includes the contribution of other muscles acting at the joint examined.

(peak-to-peak) to the input of the cathode followers. By varying the attentuation of the oscilloscope amplifier and viewing the potential change counter it was possible to show that every potential change of $100 \mu \mathrm{V}$ was being counted. In the case of the amplitude analyser the calibration waveform gave a standard figure for a 1 second period of measurement and the analyser gain was adjusted to give the correct value.

A previous study (Willison, 1964) had shown that activity measured in terms of counts per second varied considerably from one area to another in a single muscle. It was therefore necessary to take samples from many areas of each muscle. The needle was first inserted to a depth of 2.5 to $3.0 \mathrm{~cm}$. and was withdrawn by 1 to $2 \mathrm{~mm}$. after each sample had been taken. Thus five or six samples might be taken from each needle track.

In the present study the average number of samples per muscle in the healthy subjects was 16.6 and in the patients with primary muscle disease it was 16.1. Except in patients with severe weakness the activity from each area was measured over a period of 5 seconds. A few patients were unable to sustain the standard load for more than 1 to 3 seconds before the onset of tremulousness which made the electrical activity fluctuate and caused excessive needle movement.

In order to relate the count rates in patients to the presence or absence of weakness, each muscle examined was placed in one of two categories, 'strong' or 'weak', according to whether the maximum voluntary tension was within or below the range for healthy subjects (Table I). This table also shows the control group mean and its standard deviation for each muscle.

\section{RESULTS}

BICEPS BRACHII Fifteen healthy subjects and 10 patients were examined, the load on the muscle

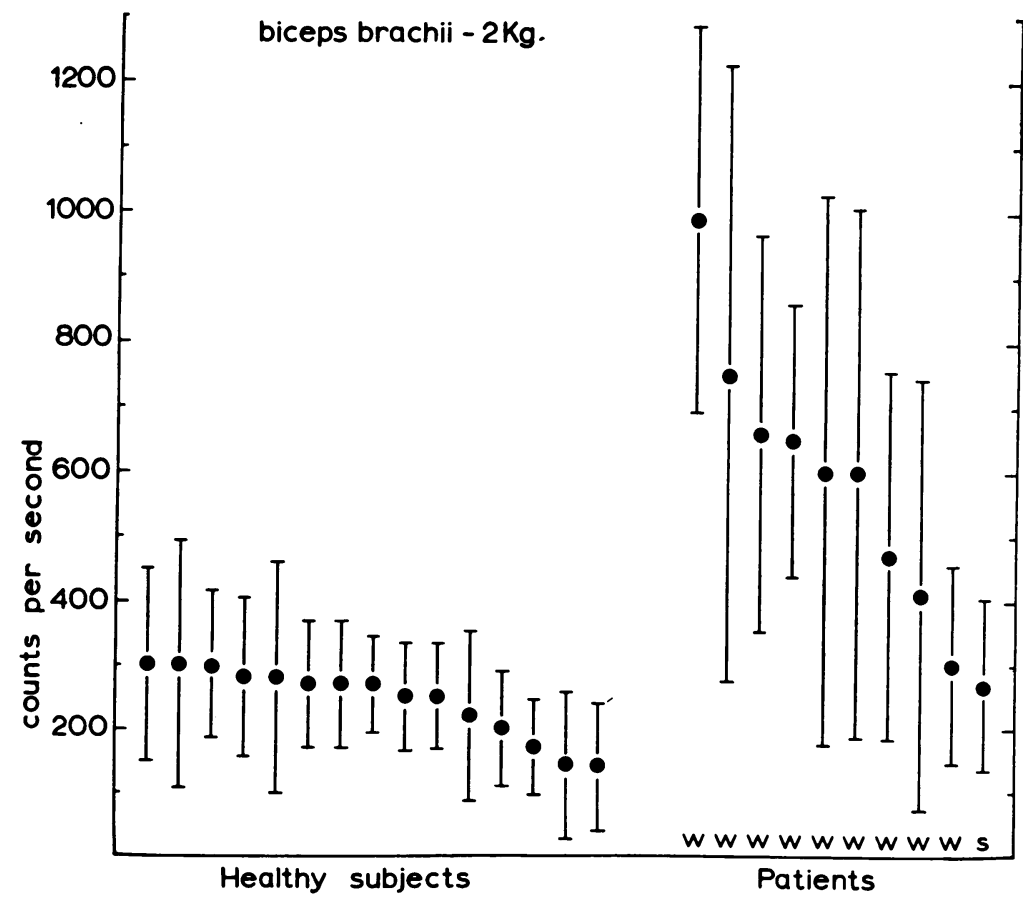

FIG. 3. Count rate of potential changes per second in biceps with $2.0 \mathrm{~kg}$. load in healthy subjects and patients with primary muscle disease. Mean values and two standard deviations are shown for each subject and patient. 
being $2 \cdot 0 \mathrm{~kg}$. Samples were usually recorded from that part of the muscle belly immediately below the fusion of long and short heads, needle insertions being made at the junction of middle and lower thirds of a line joining the tip of the acromion and the lateral epicondyle of the humerus.

The mean values of counts per second in healthy subjects ranged from 140 to 308 . These are plotted, with two standard deviations, in Figure 3. The mean figure for the whole group of control subjects was 246 counts per sec. (S.D.56). All 10 patients with muscle disease showed mean counts which were higher than the mean of the control group and eight showed counts which were significantly higher (i.e., higher than the mean of the control group +2 S.D.). It can be seen from Fig. 3 that all muscles with abnormally high counts were clinically weak according to the classification adopted here. It can also be seen that one of the patients with clinical weakness had a mean count rate which was not significantly abnormal.

TRICEPS Eleven healthy subjects and nine patients were examined, the load on the muscle being $2 \mathrm{~kg}$. The electrode was inserted at a level approximately at the junction of middle and lower thirds of a line joining the tip of the acromion to the lateral epicondyle of the humerus. The bulkiest part of the lateral head was sampled slightly in front of the coronal plane, the needle being inserted to a depth of 2 to $3 \mathrm{~cm}$. and successive samples taken during withdrawal.

The mean figure for the whole group of control subjects was 329 counts per sec. (S.D.49). Nine of the 10 patients with muscle disease showed mean counts which were higher than the mean of the control group, but in only four cases were the counts significantly higher (i.e., higher than the control mean +2 S.D.). However, it can be seen from Fig. 4 that only three of the nine patients had muscles which were clinically weak; in one patient with muscular dystrophy a significantly high count was recorded from a muscle with normal power.

VASTUS MEDIALIS This muscle was examined in 15 healthy subjects and five patients with muscle disease (in two patients the vastus medialis on both sides were examined), the load on the muscle being $5 \mathrm{~kg}$. The needle was inserted into the bulkiest portion of the muscle 8 to $10 \mathrm{~cm}$. above the level of the upper border of the patella. The mean figure for the whole group of control subjects was 246 counts per sec. (S.D.52). It can be seen from Fig. 5 that six of the seven muscles in patients with myopathy had count rates which were significantly higher than the mean of the control group, although the muscle was rated as clinically weak in only three cases. The difference between clinical assessment and quantitative electromyography, which is noticeable here, may mean nothing more than that tests of muscle power involved the whole quadriceps muscle whereas electromyography was restricted to the vastus medialis.

TIBIALIS ANTERIOR Twenty healthy subjects and 10 patients with muscle disease were examined at a load of $2 \mathrm{~kg}$. The electrode was placed into the bulky part of the muscle 8 to $10 \mathrm{~cm}$. below the tibial

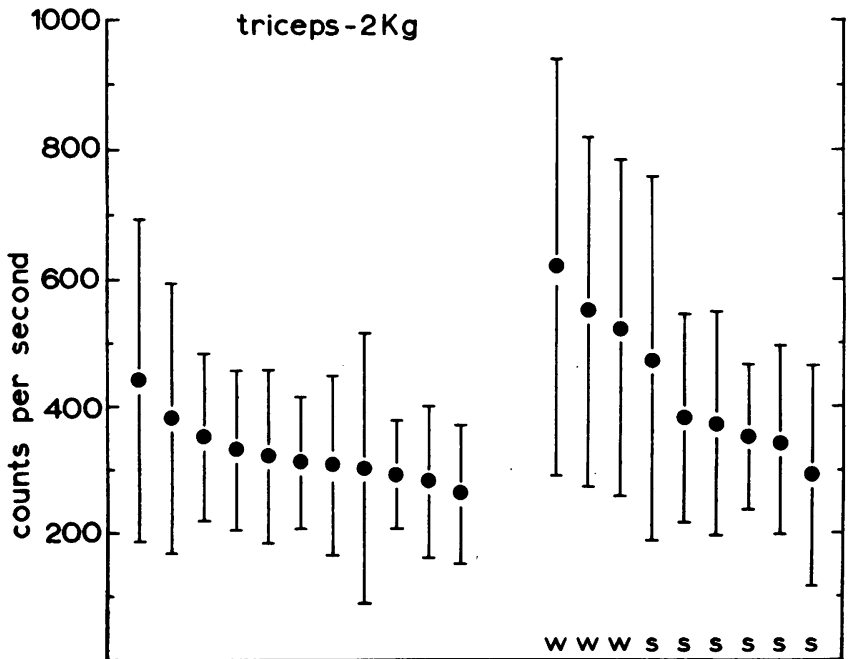

Healthy subjects

Patients
FIG. 4. Count rate of potential changes per second in triceps with $2.0 \mathrm{~kg}$. load in healthy subjects and patients with primary muscle disease. Mean values and two standard deviations are shown for each subject and patient. 


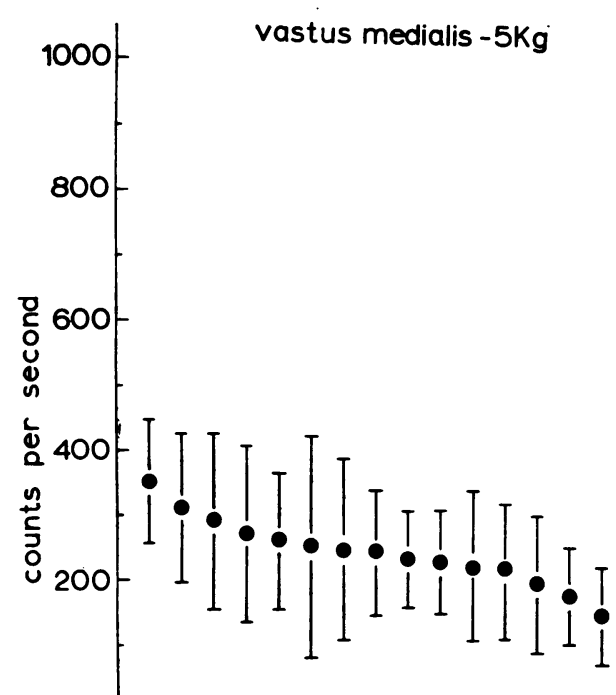

Healthy subjects

tubercle and $2-3 \mathrm{~cm}$. lateral to the anterior border of the tibia.

The mean figure for the whole group of control subjects was 295 counts per sec. (S.D.87).

It can be seen from Fig. 6 that seven out of 10

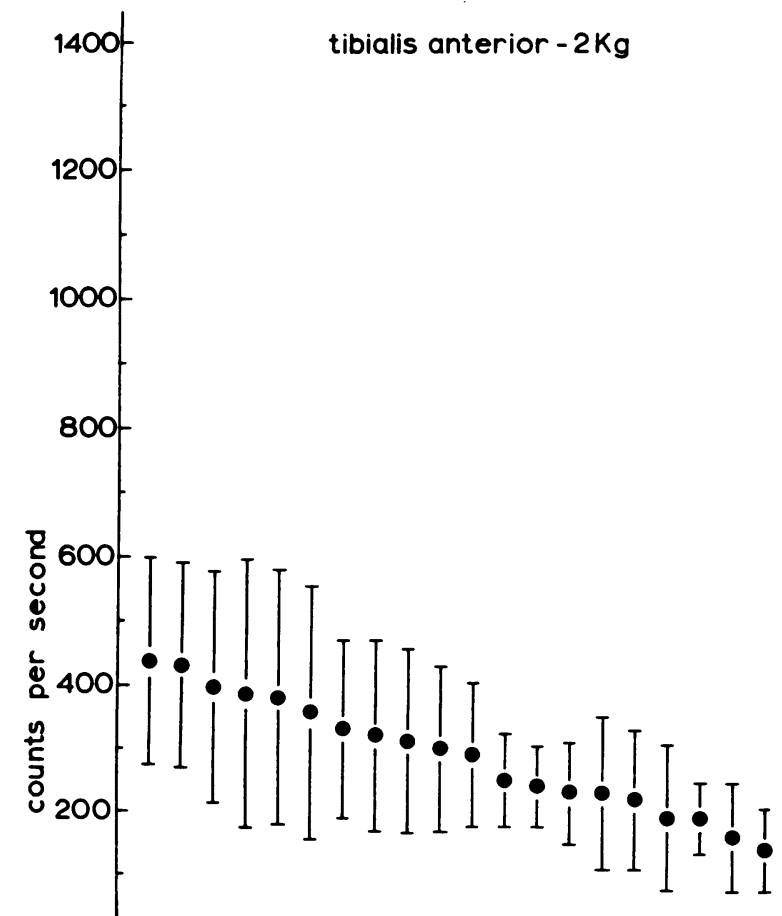

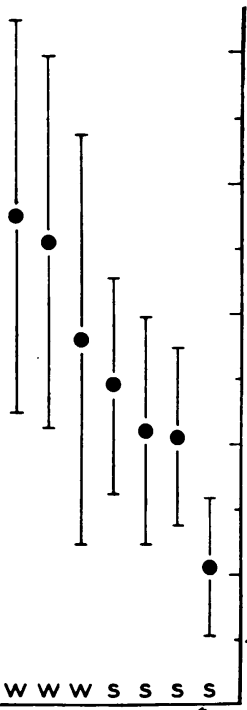

Patients
FIG. 5. Count rate of potential changes per second in vastus medialis with $5.0 \mathrm{~kg}$. load in healthy subjects and patients with primary muscle disease. Mean values and two standard deviations are shown for each subject and patient. patients with muscle disease showed mean counts which were higher than the mean of the control group, the counts being significantly higher in five cases. The correlation with clinical weakness was poor, one strong muscle from a patient showing a

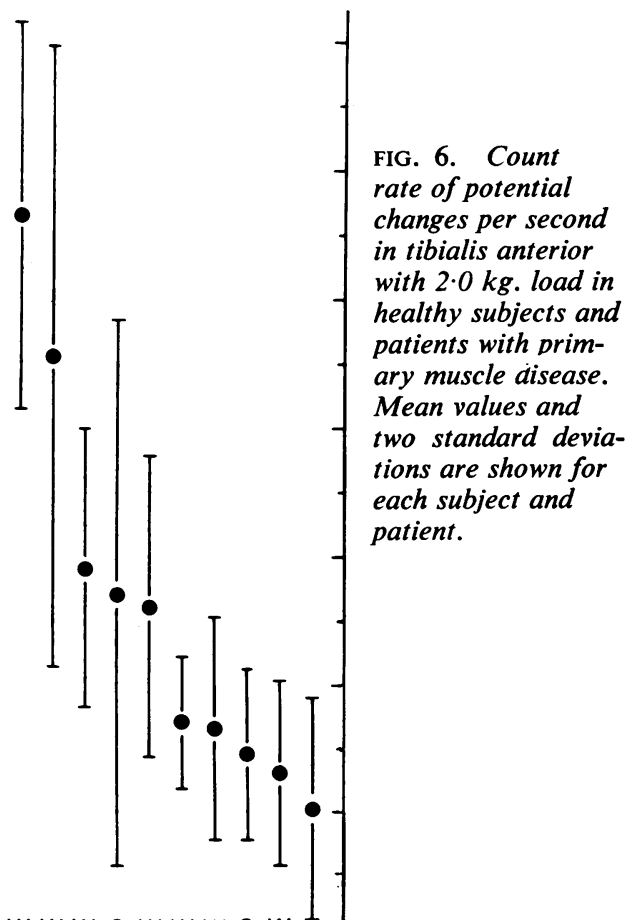


significantly high count and weak muscles from three other patients showing normal counts.

When the results for all four muscles are taken together there were 23 muscles (out of 36 examined) from patients with primary muscle disease with

$$
\begin{aligned}
& \text { Mean no. of areas } \\
& \text { sampled }
\end{aligned}
$$

\section{Control subjects}

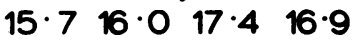

Patients

$14 \cdot 9 \quad 19 \cdot 3 \quad 16 \cdot 0 \quad 14 \cdot 8$

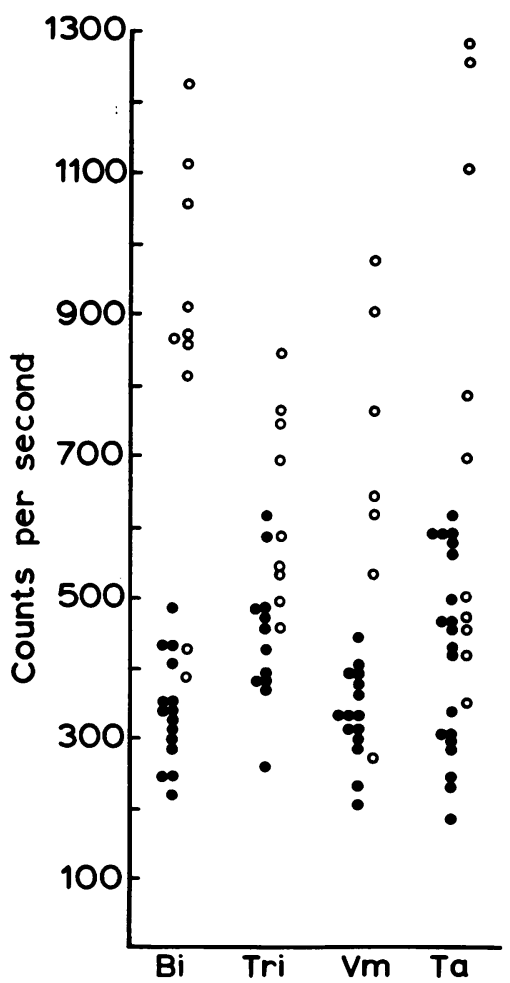

FIG. 7. Highest single values of counts found in individual healthy subjects (solid circles) and patients with primary muscle disease (open circles) in four muscles; biceps brachii (Bi), triceps brachii (Tri), vastus medialis $(\mathrm{Vm})$, and tibialis anterior (Ta). Mean numbers of areas sampled from which the highest values were selected shown at head of each column. mean count rates which were at least 2 S.D. above the control mean. None of the mean count rates in individual healthy subjects were more than $2 \cdot 3$ S.D. above the control group mean for the muscle concerned. It is clear from the data given in Figs. 3-6 that in patients with increased mean counts the count rates from one area to another varied greatly, so that scatter from the mean was increased. Figures 3-6 show the standard deviations and not the ranges. To show the true upper values which were recorded, Fig. 7 contains the highest value for each muscle examined in both controls and patients. In 23 out of 36 muscles, count rates from patients were higher than in any control subject; these 23 muscles were also those which showed significantly increased mean values.

ILLUSTRATIVE CASES The following cases illustrate these results.

Case 1 Mr. R. C. (N.H. A27309), aged 30, had suffered from dystrophy of limb girdle type since the age of 19 years. The findings in three muscles are given in Table II. Triceps was clinically normal and the mean count rate was also normal. The strength of both quadriceps was well within the normal range but the right was weaker than the left by $7 \mathrm{~kg}$. Both muscles showed high mean counts, those from the weaker muscle being 9 S.D. higher than the control mean. If the triceps alone had been examined in this patient a normal result would have been obtained; two other muscles with relatively wellpreserved function gave clearly abnormal results.

Case 2 Mr. H. S. (N.H. A5934), aged 66, had suffered from dermatomyositis for over five years and had been treated with prednisone in doses ranging from $60 \mathrm{mg}$. to $10 \mathrm{mg}$. per day for four years. Typical changes of polymyositis had been found on biopsy of the left deltoid. Table II shows the quantitative electromyographic findings.

\section{TABLE II}

RESULTS IN THREE PATIENTS WITH

\begin{tabular}{|c|c|c|c|c|}
\hline Case & Muscle & $\begin{array}{l}\text { Maximum } \\
\text { Tension } \\
\text { (kg.) }\end{array}$ & $\begin{array}{l}\text { Mean Count } \\
\text { per Second }\end{array}$ & $\begin{array}{l}\text { S.D.s above } \\
\text { Control } \\
\text { Mean }\end{array}$ \\
\hline 1 & $\begin{array}{l}\text { L. vastus medialis } \\
\mathbf{R} \text {. vastus medialis } \\
\text { R. triceps }\end{array}$ & $\begin{array}{l}30 \\
23 \\
13\end{array}$ & $\begin{array}{l}496 \\
759 \\
362\end{array}$ & $\begin{array}{l}4 \cdot 9 \\
9 \cdot 9 \\
0 \cdot 7\end{array}$ \\
\hline 2 & $\begin{array}{l}\text { L. biceps } \\
\text { R. tibialis anterior } \\
\text { R. triceps }\end{array}$ & $\begin{array}{l}12 \\
15 \\
8 \cdot 5\end{array}$ & $\begin{array}{l}990 \\
547 \\
550\end{array}$ & $\begin{array}{r}13 \cdot 1 \\
2 \cdot 9 \\
4 \cdot 5\end{array}$ \\
\hline 3 & $\begin{array}{l}\text { R. triceps } \\
\text { R. vastus medialis } \\
\text { R. tibialis anterior }\end{array}$ & $\begin{array}{r}6 \\
27 \\
0\end{array}$ & $\begin{array}{r}613 \\
424 \\
1,136\end{array}$ & $\begin{array}{l}5 \cdot 8 \\
3 \cdot 4 \\
9 \cdot 7\end{array}$ \\
\hline
\end{tabular}
PRIMARY MUSCLE DISEASE

The triceps showed a maximal tension at the lower end of the normal range, a result which probably indicated mild weakness for a powerfully built man. Although the clinical deficit was mild the mean count for this muscle was more than $4 \mathrm{~S}$. D. above the control mean. The biceps and tibialis anterior were more obviously weak 
and the mean counts were also abnormal. However, the main finding in this patient is that three muscles with slight to moderate weakness gave abnormal results.

Case 3 Mr. M. W. (M.H. K16517), aged 32 years, had suffered from muscular dystrophy since the age of 21 years. Table II shows that high mean counts were obtained for all three muscles which were examined, although one of them (vastus medialis) was not clinically affected. The findings in the tibialis anterior are of particular interest because the muscle was almost totally paralysed. In very weak and wasted muscles it is common to find rather scanty electrical activity, presumably arising from a few surviving muscle fibres lying in a mass of fat or fibrous tissue (c.f. Fig. 10 and Table I in Willison, 1964), but the present patient showed a high mean count in this severely affected muscle.

\section{DISCUSSION}

The use of rapid electronic analysis has enabled us to accumulate enough counts of the electromyogram of a muscle at a standard tension to make statistical comparisons between healthy subjects and patients.

In the present study an average number of 16 areas were sampled for each muscle and the figures obtained have confirmed the results obtained by mechanical counting given in the previous paper (Willison, 1964); they show that distinctively high counts are readily found in patients with primary muscle disease.

The choice of muscles suitable for study requires discussion. Originally we used triceps because it is the single extensor of the elbow joint. However, it is impossible to restrict the examination to single prime movers and it is obvious that the four muscles which we have examined are assisted in their actions by other muscles. For example, in the case of elbow flexion Wilkie (1950) showed that the isometric tension at a joint angle of $90^{\circ}$ fell from $20 \mathrm{M}$ dynes to $14 \mathrm{M}$ dynes when the radial nerve was blocked by local anaesthetic in the spiral groove. It may well be that the relative contributions of particular muscles to sustaining a given load vary considerably from subject to subject. This may be responsible for some of the variation in counts between subjects and is probably one factor which leads to poor correlation between maximum voluntary tension, which is produced by all the muscles acting at the joint, and the counts obtained from a single muscle at a much lower tension, i.e., 2.0 or $5.0 \mathrm{~kg}$. The problem of determining the relative contributions of individual muscles to joint action is a complicated one and requires further study.

In spite of these difficulties it was clearly necessary to study several muscles because involvement in muscular dystrophy and polymyositis may be con- fined to a few muscle groups. The muscles which were chosen all have simple actions at hinge joints, which simplify the application of a standard load to the distal end of the lever, i.e., wrist, ankle, or foot. Furthermore, each one had a substantial pulk which made sampling with a needle electrode bossible even when considerable wasting had taken place.

Because of differences in the range of counts in different muscles it was necessary to examine groups of healthy subjects in order to provide control figures for each muscle. Standard loads have been used because the electromyogram at maximal effort does not provide a useful basis for comparison of count rates for two reasons. First, maximum voluntary tensions vary a great deal from subject to subject, and secondly fluctuation of activity at maximum effort in both healthy subjects and patients leads to electrode movement and to unreliable counting. In connexion with fluctuation of effort, we observed that patients who were apparently unable to make sustained contractions during routine electromyography were able to do so with the aid of the standard load and indicator lamps.

When analysis of photographic records was used in counting potential changes it was necessary to select the areas of muscle showing high counts, as judged by the appearance of the trace on the screen of the cathode ray tube, in order to reduce the length of film to be analysed by hand. With the present method consecutive samples are taken by moving the needle without deliberately selecting areas showing high counts. Using this technique abnormalities were found to be present in 23 out of 36 muscles as judged both by the occurrence of at least one area giving rise to a figure higher than any found in the controls, and by finding that the mean value was significantly more than the control mean. Thus, although the range of the count rates which was found in different areas of individual muscles in the patients was very wide, there was good agreement between the highest value and the mean value which was estimated from all the areas sampled.

The relationship between muscle power and count rates has not been a close one. For instance, four out of 22 muscles which were classified as weak gave normal mean count rates. In the present study this did not prove to be of practical importance because in patients who had a weak muscle which gave rise to counts within the normal range, other muscles with abnormal counts were found. However, in muscles with only small areas of active tissue remaining among fat and fibrous tissue one would not expect to find high counts but in this case the low amplitude of individual spikes would be 
sufficient to establish the diagnosis. Examples were given in a previous paper (Willison, 1964). In all examinations mean amplitude was recorded, as had been done previously, but there were no cases in the present series in which the disease was so far advanced that low amplitudes became more important than high counts.

A further use of amplitude measurement is in the distinction of chronic partial denervation from myopathy. In view of the fact that highly polyphasic potentials are sometimes seen in partial denervation abnormally high count rates may be encountered during certain stages of recovery from peripheral nerve lesions. These are less likely to give rise to diagnostic difficulty if the mean amplitude of the electromyogram is also measured.

With regard to the strong muscles in our myopathic patients which showed count rates within the normal range it should not be assumed that the electromyogram was completely normal. Examination of the waveform suggested that many individual spikes were unduly brief, and in order to detect minor electromyographic changes of this kind it may be necessary to measure features such as the intervals between potential changes or the rise times of individual spikes. Preliminary measurements indicate that in patients with primary muscle disease, intervals of time between successive potential changes may be as short as 0.2 to $0.3 \mathrm{msec}$. and that these short intervals occur more frequently than in healthy subjects. The technical problems involved in the automatic analysis of spike intervals or rise times are now being studied.

\section{SUMMARY}

Electronic analysers have been used to estimate the frequency and amplitude of potential changes in the biceps brachii, triceps, vastus medialis, and tibialis anterior during voluntary effort against standard loads. Forty-five healthy subjects and 20 patients with primary muscle disease were examined. The mean number of areas sampled was 16 per muscle.

The frequency of potential changes was often increased in patients with primary muscle disease, compared with healthy subjects, both in individual areas of a muscle and in the whole muscle, as judged by the mean value of all areas sampled. The significance of these changes is discussed.

This work was carried out with the aid of a generous grant from the Muscular Dystrophy Group. We are most grateful to Professor R. W. Gilliatt and Mr. H. B. Morton for advice and discussions, and to Miss $M$. Dowling and Mrs. A. Hacking for their assistance in the laboratory. Decca Recording Studios kindly cut a gramophone disc for our use in calibrating the original analysers.

\section{REFERENCES}

Fitch, P. (1967). An analyser for use in human electromyography. Electr. Eng., 39, 240-243.

-, and Willison, R. G. (1965). Automatic measurement of the human electromyogram. J. Physiol. (Lond.), 178, 28-29P.

Wilkie, D. R. (1950). The relation between force and velocity in human muscle. Ibid., 110, 249-280.

Willison, R. G. (1963). A method of measuring motor unit activity in human muscle. Ibid., 168, 35-36P.

- (1964). Analysis of electrical activity in healthy and dystrophic muscle in man. J. Neurol. Neurosurg. Psychiat., 27, 386-394.

(1966). Some problems in the diagnosis of primary muscle disease. Proc. roy. Soc. Med., 59. 998-1000. 